\title{
Aortic valve replacement with the minimal extracorporeal circulation (Jostra MECC System) versus standard cardiopulmonary bypass: A randomized prospective trial
}

\author{
J. P. Remadi, MD \\ Z. Rakotoarivello, MD \\ P. Marticho, MD \\ F. Trojette, MD \\ A. Benamar, MD \\ H. Poulain, MD \\ C. Tribouilloy, PhD
}

Background: We prospectively evaluated a newly introduced minimal extracorporeal circulation system (Jostra MECC System; Jostra AG, Hirrlingen, Germany) for aortic valve surgery.

Method: In a prospective, randomized study, 100 patients underwent aortic valve replacement either with standard cardiopulmonary bypass $(n=50$, group $B)$ or with the MECC System $(n=50$, group B). The myocardial protection and the left vent were identical for the two groups. The intrapericardial suction device was never used (only the cell salvage device was used) to reduce the air-blood contact area.

Results: No significant differences were noted in patient characteristics and operative data between groups. Operative mortality ( $<30$ days) was $2 \%$ for group A and $4 \%$ for group B (difference not significant). From the preoperative period to the postoperative period, the increase in C-reactive protein was significantly higher for group B $(P<.001)$. The postoperative troponin I level was significantly lower in group A (mean $4.65 \pm 2.9 \mu \mathrm{g} / \mathrm{L}$ at 24 hours) than in group B $(8.2 \pm 4.4 \mu \mathrm{g} / \mathrm{L}$, $P<.03)$. On the other hand, the MECC System was associated with platelet preservation. Renal function was better preserved and the neurologic event rate was significantly lower for the MECC group $(P<.02)$.

Conclusion: The MECC System is safe and allows aortic valve replacement under the most favorable conditions. The system is more biocompatible than standard cardiopulmonary bypass and provides a good postoperative biologic profile and good clinical results, particularly for high-risk patients.

From the Cardiovascular Surgery Unit and Anaesthesiology Department, South Hospital, Amiens, France.

Received for publication Oct 9, 2003; revisions received Jan 4, 2004; accepted for publication Jan 27, 2004.

Address for reprints: J. P. Remadi, MD, Cardiovascular and Thoracic Surgery Unit, South Hospital, 80054 Amiens Cedex 1, France (E-mail: remadi.jean-paul@chuamiens.fr).

J Thorac Cardiovasc Surg 2004;128:436-41 $0022-5223 / \$ 30.00$

Copyright () 2004 by The American Association for Thoracic Surgery

doi:10.1016/j.jtcvs.2004.01.041

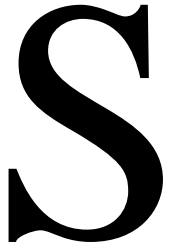

ince the beginning of the 1990s, cardiopulmonary bypass (CPB) circuits and cardioplegia procedures have achieved an optimal level. During this time, the complications related to $\mathrm{CPB}$ (inflammatory response and renal, pulmonary, and neurologic complications) remain serious problems, even though their management has improved. Coronary artery bypass grafting $(\mathrm{CABG})$ without $\mathrm{CPB}$ was therefore introduced to avoid the deleterious effect of $\mathrm{CPB}$. The new concept of CABG without CPB has restarted the search for a new concept of a less aggressive and more biocompatible CPB, minimal extracorporeal circulation (MECC). The Jostra MECC System (Jostra AG, Hirrlingen, Germany) has been used for aortic valve replacement (AVR) after a first clinical trial with CABG. We prospectively randomly assigned 100 patients to be operated on with the MECC System $(n=50)$ or with standard CPB $(\mathrm{n}=50)$. This trial is the first randomized, prospective study 
with the MECC System for isolated AVR . Limitation of deleterious effects of $\mathrm{CPB}$ is of prime necessity to maintain satisfactory results after cardiac surgery as the patient population becomes more elderly and demonstrates more associated pathologies.

\section{Patients and Methods}

From March 2001 to September 2002, we prospectively studied a series of 100 patients who underwent isolated AVR operated on with a standard $\mathrm{CPB}$ or with the MECC System. Associates procedures such as $\mathrm{CABG}$ were excluded. The study conforms to the ethical guidelines of Helsinki, as reflected by the approval of local institution's ethics committee.

\section{Randomization}

Patients were screened before AVR. Once written informed consent had been obtained, patients were randomly assigned to undergo AVR with either the MECC System ( $n=50$, group A) or standard CPB $(n=50$, group B). Exclusion criteria included severe renal failure (creatinine $>1.2 \mathrm{mg} / \mathrm{dL}$ ) because of the possibility of perioperative hemofiltration and reoperative procedures. The two groups of patients were similar with regard to the main preoperative data (Table 1). The main preoperative, intraoperative, and postoperative biologic and clinical data were collected to evaluate the evolution of these parameters.

During an initial period, the MECC system used was totally closed; AVR therefore could not be performed, because the left ventricle could not be totally discharged. Subsequently, a suction system was added to the circuit so that the AVR could be performed.

\section{Anesthesia and Surgery Protocol}

All patients received premedication with lorazepam $(2.5 \mathrm{mg}$ orally) 90 minutes before operation, morphine sulfate $(0.1 \mathrm{mg} / \mathrm{kg}$ body weight intramuscularly), and ondansetron ( $8 \mathrm{mg}$ orally) 60 minutes before transfer to the operating room. Anesthesia was induced with midazolam $(0.05-0.075 \mathrm{mg} / \mathrm{kg})$, etomidate $(0.3 \mathrm{mg} /$ $\mathrm{kg}$ ), and sufentanyl. Neuromuscular block was induced by intravenous pancuronium $(0.15 \mathrm{mg} / \mathrm{kg})$ and was maintained by continuous infusion of cisatracurium besylate (INN: cisatracurium besilate, $1.5-2.0 \mu \mathrm{g} \cdot \mathrm{kg}^{-1} \cdot \min ^{-1}$ ). Anesthesia was maintained with propofol and a continuous infusion of remifentanil (0.2-1.0 $\left.\mu \mathrm{g} \cdot \mathrm{kg}^{-1} \cdot \mathrm{min}^{-1}\right)$ or sufentanyl. A full heparin dose was given (3 $\mathrm{mg} / \mathrm{kg}$ intravenously), and the activated clotting time was maintained above 400 seconds. With the MECC System circuit a half dose (only $1.5 \mathrm{mg} / \mathrm{kg}$ ) of heparin would have been sufficient. The aortic and venous cannulas used were not precoated with heparin; therefore a full dose of heparin was used for both groups. At the end of the procedure, heparin was reversed with protamine at a 1:1 equivalent dose. Aprotinin was never used in this series.

The standard procedure was performed through a full median sternotomy. The myocardial protection consisted in a hyperkalemic warm blood cardioplegia with the CP1B product (magnesium chloride-potassium chloride-procaine chloride). This cardioplegic solution was delivered every 20 minutes. The left vent was implanted into the main pulmonary artery trunk. For groups A and group B, the mean aortic crossclamp and CPB times were, respectively, $40.6 \pm 20.7$ minutes and $71.2 \pm 23.5$ minutes versus 45.6
TABLE 1. Patient data

\begin{tabular}{|c|c|c|}
\hline & Group $A(n=50)$ & Group B $(n=50)$ \\
\hline Age $(y$, mean $\pm S D)$ & $67.8 \pm 10.8$ & $66.6 \pm 10.7$ \\
\hline Sex ratio (male/female) & 3.05 & 3.27 \\
\hline $\begin{array}{l}\text { Body mass index }\left(\mathrm{kg} / \mathrm{m}^{2},\right. \\
\text { mean } \pm \mathrm{SD})\end{array}$ & $1.86 \pm 0.17$ & $1.88 \pm 0.23$ \\
\hline \multicolumn{3}{|l|}{ Concomitant conditions (\%) } \\
\hline Diabetes mellitus & $15.3 \%$ & $12.3 \%$ \\
\hline Hypertension & $36.7 \%$ & $41.3 \%$ \\
\hline $\begin{array}{l}\text { Chronic obstructive } \\
\text { pulmonary disease }\end{array}$ & $7.3 \%$ & $8 \%$ \\
\hline $\begin{array}{l}\text { Moderate renal } \\
\text { insufficiency }\end{array}$ & $5.3 \%$ & $4.7 \%$ \\
\hline $\begin{array}{l}\text { Peripheral vascular } \\
\text { disease }\end{array}$ & $10 \%$ & $17.3 \%$ \\
\hline $\begin{array}{l}\text { Cerebrovascular } \\
\text { accident }\end{array}$ & $3.3 \%$ & $4 \%$ \\
\hline $\begin{array}{l}\text { Previous myocardial } \\
\text { infarction }\end{array}$ & $4 \%$ & $4.7 \%$ \\
\hline \multicolumn{3}{|l|}{$\begin{array}{l}\text { Left ventricular ejection } \\
\text { fraction }\end{array}$} \\
\hline Mean \pm SD & $57.6 \% \pm 3.4 \%$ & $55.7 \% \pm 4.8 \%$ \\
\hline$<40 \%(\%)$ & $10.3 \%$ & $12.7 \%$ \\
\hline \multicolumn{3}{|l|}{$\begin{array}{l}\text { Mechanical prostheses } \\
\text { (No.) }\end{array}$} \\
\hline Edwards-Mira & 25 & 24 \\
\hline Bioprostheses (No.) & 25 & 26 \\
\hline Toronto Stentless & 15 & 14 \\
\hline Carpentier-Edwards & 10 & 12 \\
\hline
\end{tabular}

All differences are not statistically significant.

\pm 17.3 minutes and $77.2 \pm 27.3$ minutes (difference not significant). Fifty percent of the aortic prostheses implanted were bioprostheses (Table 1). Red blood cell transfusions were administered if hematocrit fell below $25 \%$.

\section{Statistical Analysis}

The statistical analyses were performed with the SPSS software program (SPSS Inc, Chicago, Ill). All continuous data are expressed as mean $\pm \mathrm{SD}$. The clinical profile of the two groups was compared with analysis of the variance for continuous data and by $\chi^{2}$ analysis or the Fisher exact test for categoric data. Analysis of data with nonnormal distribution was performed with the MannWhitney test.

\section{MECC System}

The Jostra MECC System (Jostra AG, Hirrlingen, Germany) is a fully heparin-coated (Bioline-Jostra) closed-loop CPB system (Figure 1). A half dose (150 U/kg intravenously) of heparin is required. This system is composed of a membrane hollow-fiber oxygenator (Quadrox) and a centrifugal pump (Rotaflow). The tubing length does not exceed $1 \mathrm{~m} \times 2$. The pump therefore must be located near the patient's head. The blood-foreign surface contact area and the hemodilution are reduced with a $450-\mathrm{mL}$ priming solution. The system does not have cardiotomy suction. Online blood gas and saturation monitoring and a heat exchanger are incorporated. The intrapericardial suction device was not used, 

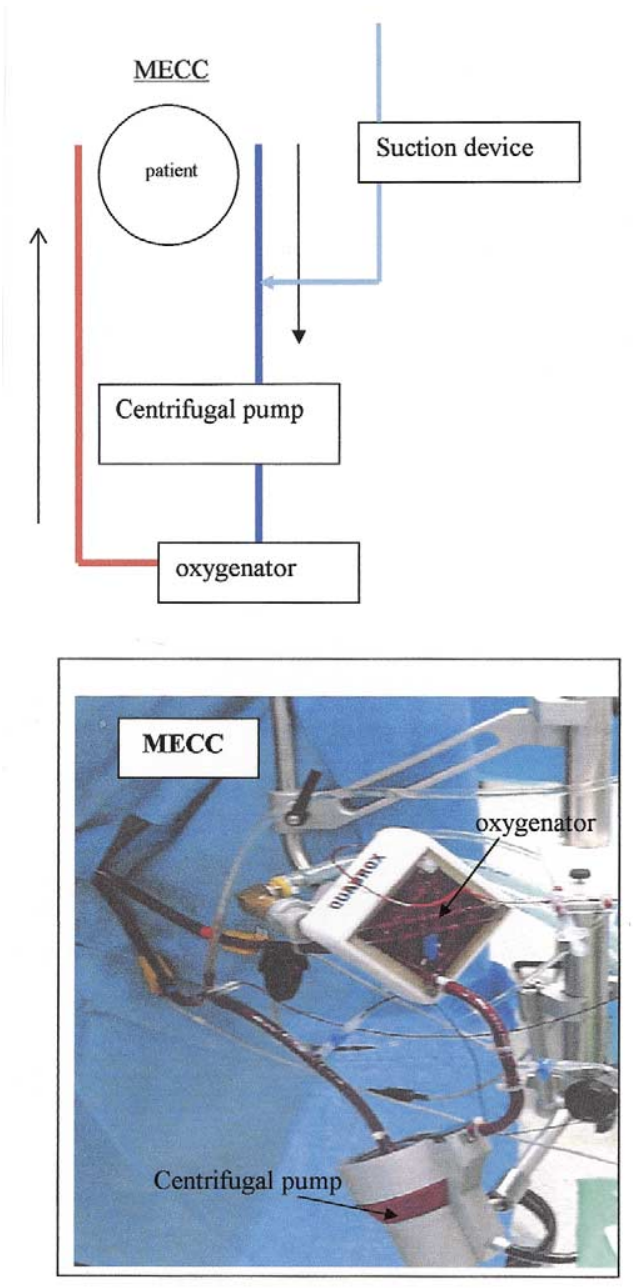

1-centrifugal pump

2-no venous reservoir: closed system

3 -tubing length $<1$ metre(priming volume $450 \mathrm{ml}$ )

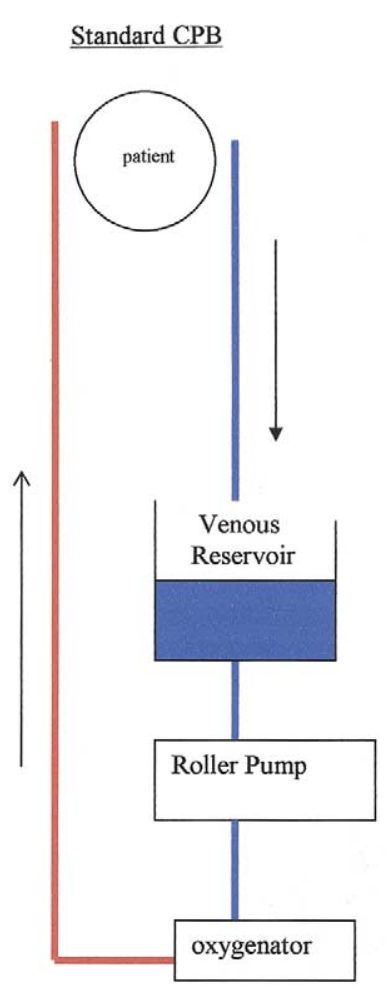

Figure 1. Jostra MECC System (left) and standard CPB (right).

and the intrapericardial blood was sucked in only with a cell salvage device. A double venous purse-string suture was systematically placed to ensure a perfect seal at the right atrial level (deairing of the system is more difficult because of the absence of venous reservoir). The MECC System was positioned closer to the operative field because the circuit is shorter than standard CPB (only $1 \mathrm{~m}$ ). From 2002 on, a suction system was added to the MECC System. This new system should be considered "semiclosed" because of the partial air-blood contact through the suction system. The myocardial protection used was a warm blood hyperkalemic cardioplegia with CP1B product (procaine).

\section{Standard CPB}

The CPB used was the same for all the patients (Figure 1). The line was not coated with heparin. The CPB was primed with $1700 \mathrm{~mL}$
Ringer lactate solution. The system contained a membrane oxygenator Cobe Optima (COBE Cardiovascular, Inc, Arvada, Colo) and a standard roller pump. The tubing length was $2.20 \mathrm{~m}$. The left ventricular vent was implanted into the pulmonary artery as for the MECC System. The intrapericardial suction device was not used, and the intrapericardial blood was sucked in only with a cell salvage device, as for the MECC System. The myocardial protection was similar to that used with the MECC System.

\section{Results}

Atrial fibrillation was the most frequent postoperative complication in both groups (31\% in group A and $36 \%$ in group $\mathrm{B}, P=.72)$ and was treated with amiodarone. The operative mortalities ( $<30$ days) were $2 \%$ for group A and $4 \%$ for group $\mathrm{B}(P=.2)$. 


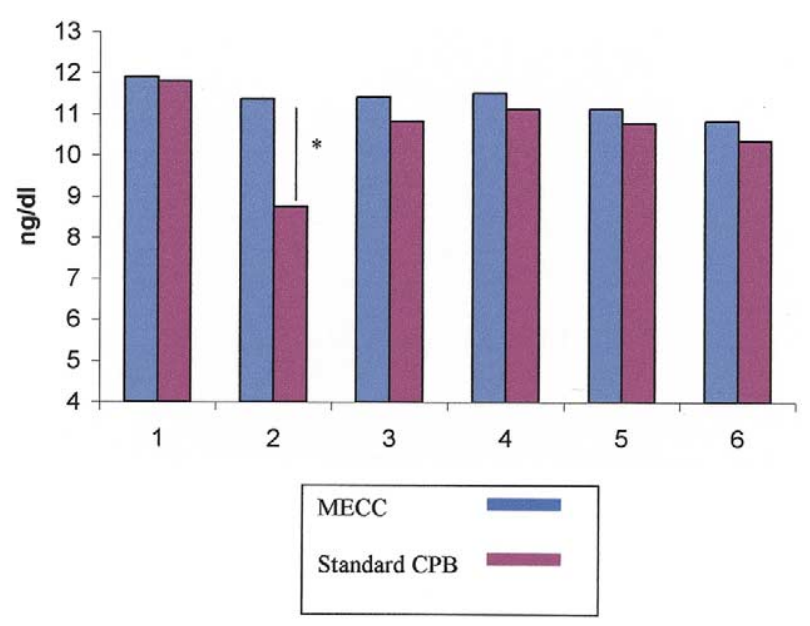

Figure 2. Hemoglobin evolution. 1, Preoperative; 2, after CPB or MECC; 3, postoperative hour 6; 4, postoperative day 1; 5, postoperative day 2; 6, discharge. Hemoglobin level was significantly lower after MECC (light bars) than after standard CPB (dark bars). Asterisk indicates $\boldsymbol{P}<.05$.

Weaning from MECC was easy for all but 1 patient, who required a 30-minute period of circulatory assistance with inotropic drugs. Low cardiac output syndrome rates in groups A and group B were $2 \%$ and $6 \%$, respectively $(P<$ $.03)$. In group A, 5 patients required dobutamine $(>5 \mu \mathrm{g}$. $\left.\mathrm{kg}^{-1} \cdot \min ^{-1}\right)$ or norepinephrine, and no IABCP was used. In group $\mathrm{B}, 10$ patients needed inotropic drugs $(P<.02)$.

During the procedure, the mean blood pressure was higher and more stable in group A (mean $71 \mathrm{~mm} \mathrm{Hg}$ ) than in group B (mean $58 \mathrm{~mm} \mathrm{Hg}$, difference not significant). During MECC and standard CPB hematocrit levels decrease were $4.25 \%$ and $8.52 \%$, respectively $(P<.01)$. The perioperative red blood cell transfusion rates were $8.7 \%$ for group $\mathrm{A}$ and $15.9 \%$ for group $\mathrm{B}(P<.01)$. The mean postoperative blood loss volumes for groups $\mathrm{A}$ and $\mathrm{B}$ were $752.9 \pm 165.7 \mathrm{~mL}$ and $789.5 \pm 21 \mathrm{~mL}$, respectively (difference not significant). From the preoperative period to the patient discharge, the hemoglobin and hematocrits in group A were stable, with only $0.82 \mathrm{~g} / \mathrm{L}$ and $0.61 \%$ decreases, respectively (Figure 2 ). In group $\mathrm{B}$, there was a significantly stronger decrease in hematocrit (Figure 2). After the first 48 hours, no significant differences were noted between the two groups with respect to hemoglobin and hematocrit evolution (Figure 2). The postoperative red blood cell transfusion rates in the two groups were therefore similar $(7 \%$ and $9 \%$ for groups $\mathrm{A}$ and $\mathrm{B}$, respectively, difference not significant).

The evolution of platelet and leukocyte counts were correlated with a stronger inflammatory syndrome in group $\mathrm{B}$ (CPB) (Table 2). Likewise, the increase in C-reactive protein was higher for group $\mathrm{B}$ between the preoperative and postoperative periods (Table 2). The postoperative tro-
TABLE 2. Biologic data

\begin{tabular}{cccc}
\hline & $\begin{array}{c}\text { Group A } \\
\text { (n= 50) }\end{array}$ & $\begin{array}{c}\text { Group B } \\
(\mathbf{n}=\mathbf{5 0})\end{array}$ & $\begin{array}{c}\boldsymbol{P} \\
\text { value }\end{array}$ \\
\hline $\begin{array}{c}\text { Leukocytes (cells/mm }{ }^{3} \text { ) } \\
\text { Preoperative }\end{array}$ & $7950 \pm 2540$ & $7530 \pm 3200$ & NS \\
Postoperative h 6 & $12.900 \pm 3510$ & $13.900 \pm 2820$ & NS \\
Postoperative d 5 & $8600 \pm 2340$ & $8230 \pm 3200$ & NS \\
Platelets (cells/mm ${ }^{3}$ ) & & & \\
Preoperative & $245.182 \pm 32.254$ & $251.581 \pm 42.400$ & NS \\
Postoperative h 6 & $179.142 \pm 21.320$ & $122.910 \pm 24.350$ & $<.04$ \\
Postoperative d 5 & $221.285 \pm 41232$ & $215.342 \pm 32.600$ & NS \\
Creatinine (mg/dL) & & & \\
Preoperative & $78 \pm 17.2$ & $79 \pm 12.5$ & NS \\
Postoperative h 6 & $88 \pm 22.2$ & $98.5 \pm 24.3$ & $<.03$ \\
Postoperative d 5 & $83 \pm 27.2$ & $88 \pm 25.2$ & NS \\
Urea (mmol/L) & & & \\
Preoperative & $7.2 \pm 2.1$ & $7.4 \pm 2.1$ & NS \\
Postoperative h 6 & $10.4 \pm 3.4$ & $12.3 \pm 4.8$ & $<.02$ \\
Postoperative d 5 & $7.6 \pm 2.1$ & $8.1 .3 \pm 4$ & NS \\
C-reactive protein & & & \\
$\quad$ (mg/L) & & & \\
Preoperative & $7.5 \pm 2.2$ & $6.4 \pm 3.3$ & NS \\
Postoperative h 72 & $39.5 \pm 18.5$ & $68.6 \pm 28.5$ & $<.001$ \\
\hline
\end{tabular}

NS, Not statistically significant.

ponin I level was significantly lower in group A (MECC) (mean $4.65 \pm 2.9 \mu \mathrm{g} / \mathrm{L}$ in the first 24 hours) than in group B $(9.5 \pm 4.4 \mu \mathrm{g} / \mathrm{L}, P<.03$; Figure 3$)$.

The mean time to extubation for group A was $8.8 \pm 4.1$ hours, lower than that for group B $(8.2 \pm 5.1$ hours, difference not significant). The mean intensive care stay for group A was $42.2 \pm 3.6$ hours, also lower than that for group B (48.2 \pm 4.3 hours, difference not significant). From the intensive care unit, the patients were transferred to the surgery unit for mean stays of $6.2 \pm 3.3$ days for group A and $6.5 \pm 2.4$ days for group B (difference not significant).

Patients in group B had significantly higher postoperative levels of creatinine and urea (Table 2). Consistent with this, group B required more diuretics than did group A (22\% vs $9.5 \%, P<.01)$. Three patients in group $\mathrm{B}$ and only 1 in group A required hemofiltration (difference not significant). Postoperative focal neurologic complications (aphasia, focal motor, sensory cranial abnormality) and altered mental status (mainly disorientation) were significantly $(P<.02)$ more frequent in group $\mathrm{B}(\mathrm{n}=7)$ than in group $\mathrm{A}(\mathrm{n}=2)$.

\section{Discussion}

Since the early 1990s, the patients admitted for and operated on in cardiac surgery have had an increase in risk, with a higher mean Parsonnet score. In fact, older age at operation and respiratory or renal insufficiencies are not longer considered exclusion criteria. Improvements in surgical, anesthesia, and CPB techniques are all important in achieving satisfactory postoperative results despite of worsening preoperative clinical status of the patient population. 

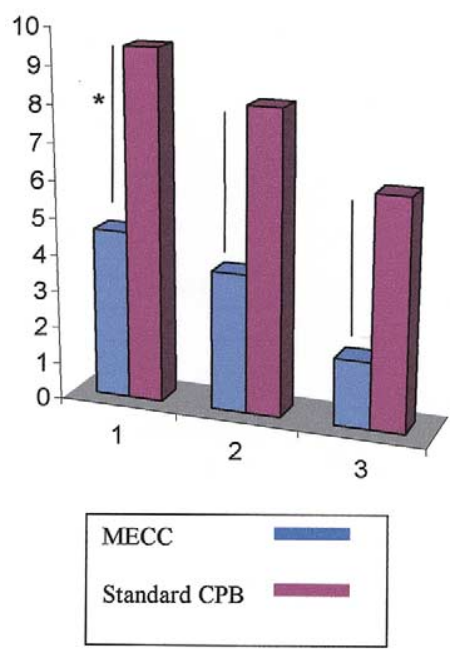

Figure 3. Troponin T evolution. 1, Postoperative hour 3; 2, postoperative day $1 ; 3$, postoperative day 2 . Troponin $T$ level was significantly lower with MECC during postoperative period. This result outlines better preservation of myocardial preservation with MECC System (light bars) than with standard CPB (dark bars). Asterisk indicates $P<.05$.

Contact of blood with artificial surfaces during CPB involves a pathophysiologic response similar to that of posttraumatic shock, the so-called postperfusion syndrome, which may lead to the systemic inflammatory response syndrome, adult respiratory distress syndrome, sepsis, and multiorgan failure..$^{1-3}$ To improve biocompatibility, artificial surfaces are heparin coated with various materials in an effort to mimic the natural endothelial surface. The centrifugal pump also may improve the biocompatibility, as may exclusive use of the cell salvage device to limit the air-blood contact area. ${ }^{4}$ The MECC System combines these elements, which could explain inflammatory syndrome decrease ${ }^{5}$ and the good clinical and biologic results described in this prospective series.

Heparin-coated artificial surfaces was first used by Gott. The evidence that use of surface-heparinized equipment would avoid the need for full systemic heparinization led to the introduction of heparin-coated CPB circuits in combination with reduced systemic heparin levels. ${ }^{6-9}$ Currently available heparin-coated circuits have been reported to be associated with reduced expression of systemic inflammatory response syndrome; reduced activation of neutrophils, monocytes, eosinophils, platelets, and the complement system; and limitation of cytokine release and reduced stimulation of the coagulation system. ${ }^{8}$ In our series, the full heparin dose was given. Nevertheless, in our prospective trial we have shown for AVR surgery better clinical results, preservation of renal function, reduced cardiac enzyme re- lease, and better preservation of platelet count. Indeed, the MECC System represents the successful combination of decreased deleterious CPB effects (as in off-pump CABG) and $\mathrm{CPB}$ advantages for hemodynamic and surgical procedure management. The inflammatory syndrome is especially reduced because of decreased hemodilution ${ }^{10,11}$ and air-blood contact area reduction. ${ }^{12}$ The decreased $\mathrm{S} 100 \beta$ protein release during MECC versus standard CPB might show a lesser neurologic toxicity associated with MECC. ${ }^{13,14}$ The inflammatory syndrome is reduced with the MECC System, as shown by Fromes and colleagues. ${ }^{5}$ We therefore can expect reduced postoperative morbidity. The patients operated on for AVR are often included in high-risk patient groups: age older than 65 years, renal dysfunction, and respiratory failure. The MECC System is therefore particularly interesting for AVR. In our prospective, randomized trial, the postoperative biologic and clinical data evolution were better for the MECC group, particularly for high-risk patients. Thus in elderly patients the MECC System could reduce the renal effect and cerebral injury well described in previous studies. ${ }^{13-15}$ The lowering of inflammatory syndrome and thus greater hemodynamic stability during the procedure could explain the results for renal and neurologic preservation.

Use of the MECC System as a "semiclosed" system with aortic and pulmonary artery vent allowed AVR to be performed without losing its biologic advantage, as shown in this study. The left ventricular vent for performing the AVR is implanted in the pulmonary artery trunk, rather than directly in the left ventricle, to reduce the air-blood contact area during aortic crossclamping. The vent could be implanted in the left atrium with a low depression to avoid air-blood contact.

A learning curve for this technique is necessary for the surgical and anesthetic team. The MECC System offers less safety than standard CPB because of the absence of venous reservoir. A risk of gas embolism exists if there is an air-intake on the venous side. We therefore performed two purse-string sutures on the venous side. Currently, we have performed 400 procedures with the MECC System, and we have encountered 3 cases of air intake on the venous side. None of these 3 adverse events had consequences for the patients. In all cases deairing was achieved without any problems, and the air was stopped on the anterior part of the oxygenator.

We have performed a few mitral operations with the MECC System. However, a suction device is necessary to drain the operative field into the left atrium, because the blood volume is too high to suck in to the cell salvage device. For mitral procedures, the left vent in the pulmonary artery is not sufficient and a left intra-atrial vent is necessary. 


\section{Conclusion}

The Jostra MECC System is safe, allowing AVR surgery under optimal conditions. The system is more biocompatible than standard CPB and provides a good postoperative biologic profile and good clinical results, particularly for high-risk patients.

\section{References}

1. Butler J, Rocker GM, Westaby S. Inflammatory response to cardiopulmonary bypass. Ann Thorac Surg. 1993;55:552-9.

2. Liebold A, Keyl C, Birnbaum DE. The heart produces but the lungs consume proinflammatory cytokines following cardiopulmonary bypass. Eur J Cardiothorac Surg. 1999;15:340-5.

3. Rothenburger M, Soeparwata R, Deng MC, Schmid C, Berendes E, Tjan TD, et al. Prediction of clinical outcome after cardiac surgery: the role of cytokines, endotoxin, and anti-endotoxin core antibodies. Shock. 2001;16(Suppl 1):44-50.

4. Alamanni F, Parolari A, Zanobini M, Porqueddu M, Dainese L, Bertera A, et al. Centrifugal pump and reduction of neurological risk in adult cardiac surgery. J Extra Corpor Technol. 2001;33:4-9.

5. Fromes Y, Gaillard D, Ponzio O, Chauffert M, Gerhardt M, Deleuze P, et al. Reduction of the inflammatory response following coronary bypass grafting with total minimal extracorporeal circulation. Eur J Cardiothorac Surg. 2002;22:527-33.

6. Wendel HP, Ziemer G. Coating techniques to improve the hemocompatibilty of artificial devices used for extracorporeal circulation. Eur J Cardiothorac Surg. 1999;16:342-50.
7. Fujita M, Ishihara M, Ono K, Hattori H, Kurita A, Shimizu M, et al. Adsorption of inflammatory cytokines using a heparin-coated extracorporeal circuit. Artif Organs. 2002;26:1020-5.

8. Koster A, Fischer T, Praus M, Haberzettl H, Kuebler WM, Hetzer R, et al. Hemostatic activation and inflammatory response during cardiopulmonary bypass: impact of heparin management. Anesthesiology. 2002;97:837-41

9. Hsu LC. Heparin-coated cardiopulmonary bypass circuits: current status. Perfusion. 2001;16:417-28.

10. Nollert G, Sperling J, Sakamoto T, Jaeger BR, Jonas RA. Higher hematocrit improves liver blood flow and metabolism during cardiopulmonary bypass in piglets. Thorac Cardiovasc Surg. 2001;49:22630.

11. DeFoe GR, Ross CS, Olmstead EM, Surgenor SD, Fillinger MP, Groom RC, et al. Lowest hematocrit on bypass and adverse outcomes associated with coronary artery bypass grafting. Northern New England Cardiovascular Disease Study Group. Ann Thorac Surg. 2001; 71:769-76

12. Schonberger JP, Everts PA, Hoffmann JJ. Systemic blood activation with open and closed venous reservoirs. Ann Thorac Surg. 1995;59: 1549-55.

13. Mongero LB, Beck JR, Manspeizer HE, Heyer EJ, Lee K, Spanier TA, et al. Cardiac surgical patients exposed to heparin-bonded circuits develop less postoperative cerebral dysfunction than patients exposed to non-heparin-bonded circuits. Perfusion. 2001;16:107-11.

14. Nollert G, Reichart B. Cardiopulmonary bypass and cerebral injury in adults. Shock. 2001;16(Suppl 1):16-9.

15. Dehne MG, Sablotzki A, Muhling J, Dehne KL, Rohrig R, Hempelmann G. Renal effects of cardiopulmonary bypass in the elderly. Perfusion. 2002;17:205-9.

\section{Authoritative}

The Journal of Thoracic and Cardiovascular Surgery is the most frequently cited thoracic/cardiovascular surgery journal in the Science Citation Index. An article in JTCVS is cited on average almost twice as often as those in the closest cardiothoracic journal. 